\title{
Optimum Design of Reinforced Concrete Rectangular Columns Subjected to Axial Compression and Biaxial Bending Moments
}

\author{
By Fouad A. Mohammad \\ Dana A. Seyan
}

This study investigates the optimum design in terms of the minimum cost of reinforced concrete rectangular columns subjected to axial compression force and biaxial bending moments about $x$ and $y$ axes. For the optimisation process, the Generalised Reduced Gradient (GRG) technique, which is embedded within Excel Solver add-in tool, was implemented. The GRG method was adopted because of its robustness and efficiency in dealing with a wide range of engineering problems as demonstrated by several works available in the literature. GRG is regarded as one of the best deterministic local optimisation methods. Equally important, the GRG is a part and parcel of Microsoft Excel which means that there is no need to pay for an extra licence to run any optimisation problem. The formulated models for the design of reinforced concrete columns and the imposed constraints were based on the provisions of the Eurocode 2 (EC2). The design variables were the cross sectional dimensions (width and depth) and the reinforcing steel area. It is worthwhile to mention that the position and orientation of neutral axis were also considered as design variables in order to avoid solving the highly nonlinear simultaneous equations which are time consuming and do not necessarily lead to a convergent solution. Several design parameters, such as materials cost ratios and depth to width ratios were tested. Consequently, optimum design charts were developed for a wide range of practical combinations of axial compression forces and eccentricities in both $x$ and $y$ directions. Following a comprehensive investigation of the minimum cost problems carried out for different cases, one can conclude that a variation of the depth to width ratio may have a noticeable effect on the optimum width, depth and area of steel only when the eccentricity in y direction (ey) is much greater than the eccentricity in $x$ direction (ex). Furthermore, the effect of steel to concrete unit cost ratio $(\mathrm{Cs} / \mathrm{Cc})$ is more obvious at larger loads and higher eccentricities.

Keywords: Biaxial bending, Design charts, Eurocode 2 (EC2), Excel Solver, Generalized Reduced Gradient (GRG), Optimisation, Reinforced concrete column

* Senior Lecturer, Nottingham Trent University, UK.

† MSc Student, Nottingham Trent University, UK. 


\section{Introduction}

The theory of optimisation, as Ravindran et al. (2006) stated, is a system "of numerical methods and mathematical results for finding and identifying the best candidate from a collection of alternatives without having to explicitly enumerate and evaluate all possible alternatives. This means that optimisation might be considered as a time-saving task enabling the expenditure of less effort for achieving a superior outcome.

Structural optimisation is a powerful mathematical technique which can be utilised to design and generate products and structures both economically and efficiently. Different optimisation methods have been developed to manage different problems including Generalised Reduced Gradient (GRG), Sequential Quadratic Programming (SQP) and Genetic Algorithms (GA), (Rao, 2009). Accordingly, these methods have become the basis for a number of commercially available optimisation packages such as Matlab, Optima and more interestingly the Microsoft Excel Solve.

The GRG method was adopted in this work because of its robustness and efficiency in dealing with a wide range of engineering problems as demonstrated by several publications including the work of (Arora, 2011), (Belegundu and Chandrupatla, 2011), (Bhalchandra and Adsul, 2012) and (Faluyi and Arum 2012). In addition, Yeniay (2005) emphasised that several comparative studies proved the GRG method as one of the best deterministic local optimisation methods. Equally important, the GRG is a part and parcel of Microsoft Excel which means there is no need to pay for an extra license to run any optimisation problem as otherwise would be the case when using purposed built optimisation software (Faluyi and Arum, 2012).

The optimum design of structures has been the topic of innumerable studies of structural design. Rapid progress in computing power and the development of new techniques in adaptive searching have provided the potential for considerable changes in this area over recent decades. A designer's objective is to devise an "optimal solution" for the structural design under consideration, which normally suggests the most cost-efficient structure that meets functional specifications, (Rafiq, 1995).

Reinforced concrete columns, owing to the complex nature of the governing design relationships, are highly multidimensional optimisation issues. A reinforced concrete column can be subjected to a combination of axial load and bending action. The bending acting on the column might be uniaxial or biaxial. The number, size and location of bars within the column section are factors affecting the efficiency, load-carrying capacity and serviceability conditions of the column. A combination of all of the mentioned necessities and an interrelationship between these criteria makes column design a complex problem, (Rafiq, 1995).

In reinforced concrete framed structures, almost all exterior columns and some interior columns with different adjacent beam spans or supporting unsymmetrical load patterns on the floors area are frequently subjected to biaxial bending, (Rafiq and Southcombe, 1998). 


\section{Design Formulation}

A rectangular concrete column section under axial load and biaxial bending is selected. It is symmetrically reinforced with two layers of reinforcement (four bars) as shown in Figure 1.

Figure 1. A Reinforced Concrete Rectangular Column Section Subjected to Biaxial Loading

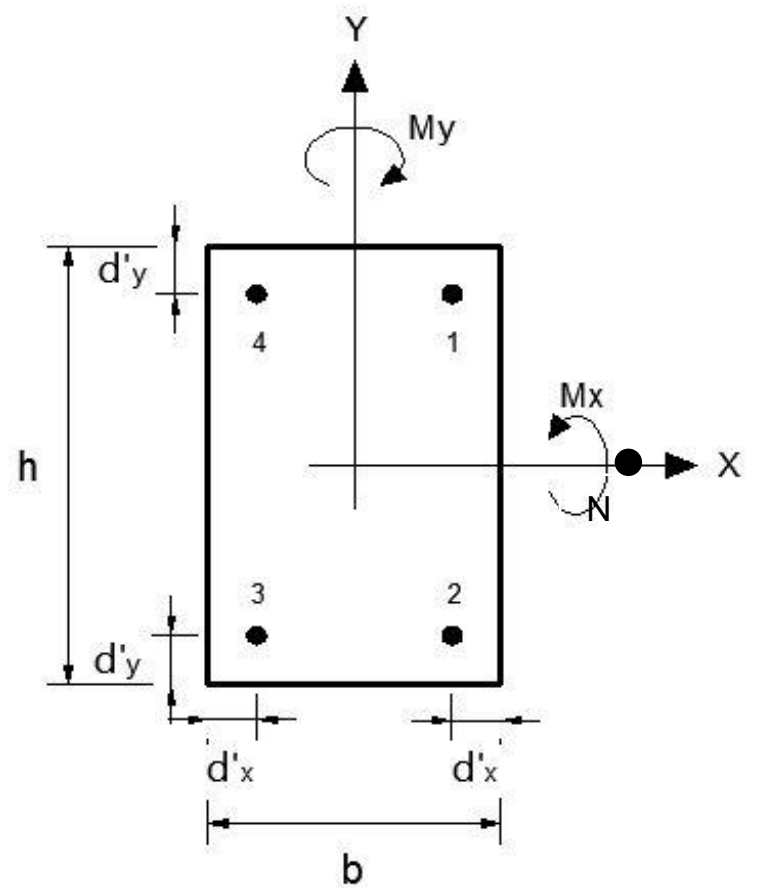

The corresponding strain, stress and force diagrams on the section at the ultimate load are illustrated in Figure 2, whereas, the location of the neutral axis specified in terms of two parameters $\alpha$ and $\beta$ is shown in Figure 3. For a specified position and direction of the neutral axis, the strain diagram can be set with the maximum strain in the concrete of $\varepsilon_{\mathrm{cu}}=0.0035$, (Euroccode 2, 2004).

As the direction of the applied load is shown in Figure 2, the maximum compressive strain in concrete $\varepsilon_{c u}$ will occur at the top right-hand corner of the section. The coordinates $\mathrm{X}_{\mathrm{i}}$ and $\mathrm{Y}_{\mathrm{i}}$ for each steel bar, can be defined with respect to the centroid of the column cross section. Accordingly, the strain in steel bar $i$ can mathematically be expressed as, (Bhatt et al., 2013):

$\varepsilon_{\text {si }}=\varepsilon_{\text {cu }}\left\{1+\frac{\left(\mathrm{X}_{\mathrm{i}}-0.5 \mathrm{~b}\right)}{\beta \mathrm{b}}+\frac{\left(\mathrm{Y}_{\mathrm{i}}-0.5 \mathrm{~h}\right)}{\alpha \mathrm{h}}\right\}$

The stress in steel bar $\mathrm{i}\left(\mathrm{f}_{\mathrm{si}}\right)$ will be:

$\mathrm{f}_{\mathrm{gi}}=\mathrm{E} * \varepsilon_{\mathrm{gi}} \quad$ where $\left|\mathrm{f}_{\mathrm{si}}\right| \leq 0.87 \mathrm{f}_{\mathrm{yk}}$ 
The force resisted by steel bars is:

$\mathrm{F}_{\mathrm{s}}=\Sigma \mathrm{A}_{\mathrm{gi}} * \mathrm{f}_{\mathrm{gi}}$

Moments $\mathrm{M}_{\mathrm{xs}}$ and $\mathrm{M}_{\mathrm{ys}}$ resisted by steel bars about the centroid of the column section are:

$$
\begin{aligned}
& \mathrm{M}_{\mathrm{xs}}=\Sigma \mathrm{A}_{\mathrm{si}} * \mathrm{f}_{\mathrm{si}} *\left(\frac{\mathrm{h}}{2}-\mathrm{d}_{\mathrm{y}}^{\prime}\right) \\
& \mathrm{M}_{\mathrm{ys}}=\Sigma \mathrm{A}_{\mathrm{si}} * \mathrm{f}_{\mathrm{si}} *\left(\frac{\mathrm{b}}{2}-\mathrm{d}_{\mathrm{x}}^{\prime}\right)
\end{aligned}
$$

Figure 2. Strain, Stress and Force Diagrams of Column Cross Section under Biaxial Loading, EC2

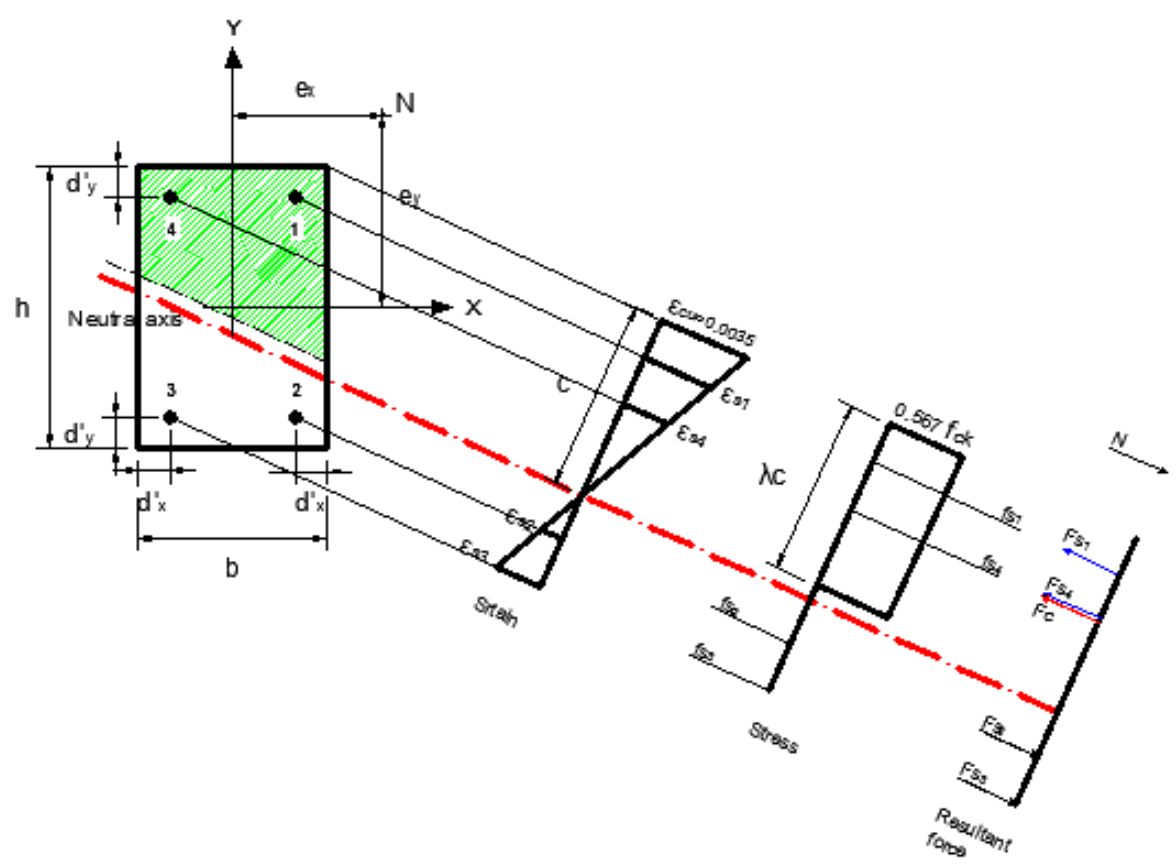

Figure 3. Column with the Neutral Axis Inclined to $x$-axis

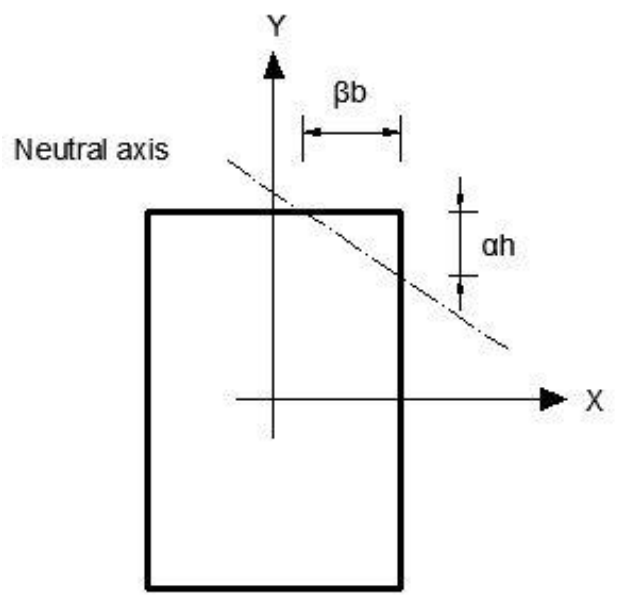


The force and moment resisted by the concrete compression area depends on the location and orientation of the neutral axis. Five possible cases may be investigated as described below.

Case $1(\lambda \beta \leq 1.0$ and $\lambda \alpha \leq 1.0)$

The triangular shape of the stress block indicated in Figure 4 represents a column subjected to a relatively low axial load. It is worth noting that $\lambda$ is a factor that defines the depth of a concrete compression block with respect to the neutral axis. It has a value of 0.8 for $\mathrm{f}_{\mathrm{ck}} \leq 50 \mathrm{MPa}$ (Euroccode 2, 2004).

Figure 4. Neutral Axis position for Case 1

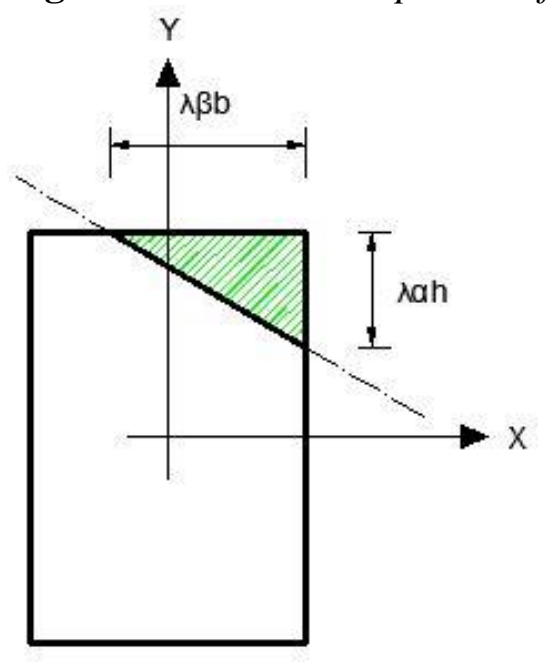

$$
\begin{aligned}
& \mathrm{F}_{\mathrm{c}}=0.567 \mathrm{f}_{\mathrm{ck}}(0.5 * \lambda \alpha \mathrm{h} * \lambda \beta \mathrm{b}) \\
& \mathrm{M}_{\mathrm{xc}}=\mathrm{F}_{\mathrm{c}} *\left(0.5 \mathrm{~h}-\frac{\lambda \alpha \mathrm{h}}{3}\right) \\
& \mathrm{M}_{\mathrm{yc}}=\mathrm{F}_{\mathrm{c}} *\left(0.5 \mathrm{~b}-\frac{\lambda \beta \mathrm{b}}{3}\right)
\end{aligned}
$$

Case $2(\lambda \beta>1.0$ and $\lambda \alpha \leq 1.0)$

According to the trapezoidal stress block presented in Figure 5, the axial load is increased and the bending moment of the $\mathrm{x}$-direction is more than the bending moment of the y-axis. 
Figure 5. Neutral Axis Position for Case 2

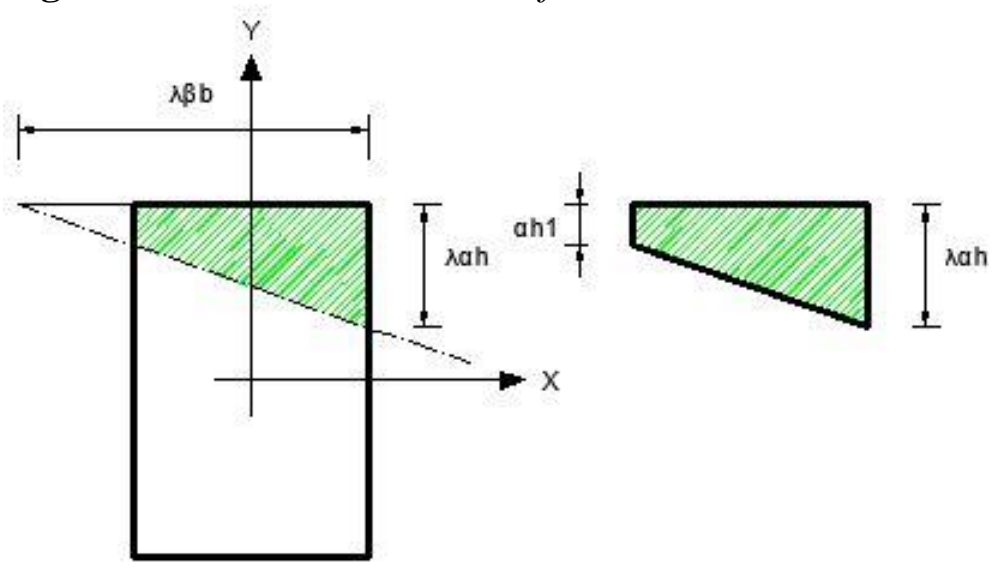

Using similarity of triangles gives:

$$
\begin{aligned}
& \alpha h 1=\frac{\alpha h}{\beta b}(\lambda \beta b-b)=\alpha h\left(\lambda-\frac{1}{\beta}\right) \\
& F_{c}=0.567 f_{c k}\{0.5(\alpha h 1+\lambda \alpha h) b\} \\
& M_{x c}=F_{c} *(0.5 h-\bar{y}) \\
& M_{y c}=F_{c} *(0.5 b-\bar{x})
\end{aligned}
$$

The location of the centroid with respect to the right face of the trapezium is:

$\overline{\mathrm{x}}=\frac{\mathrm{b}}{3} \frac{\left(2 \mathrm{~h}_{1}+\lambda \mathrm{h}\right)}{\left(\mathrm{h}_{1}+\lambda \mathrm{h}\right)}$

The location of the centroid with respect to the top face of the trapezium is:

$\bar{y}=\frac{\alpha}{3} \frac{\left(h_{1}^{2}+\lambda^{2} h^{2}+\lambda h_{1} h\right)}{\left(h_{1}+\lambda h\right)}$

Case $3(\lambda \beta \leq 1.0$ and $\lambda \alpha>1.0)$

From the trapezoidal stress block shown in Figure 6 the bending moment of the $y$-axis is dominant. 
Figure 6. Neutral Axis Position for Case 3

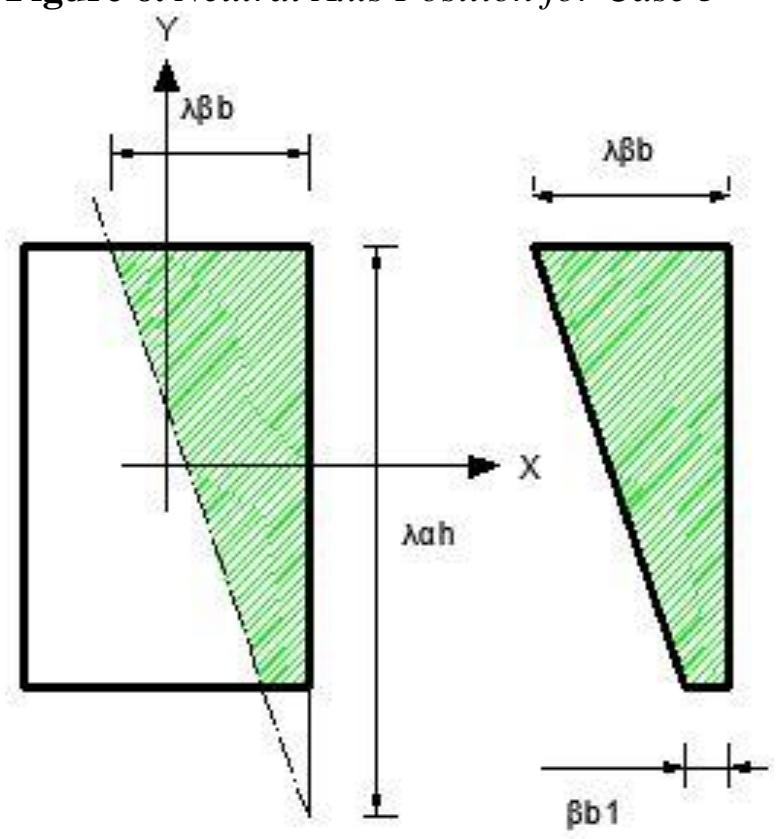

$$
\begin{aligned}
& \beta b 1=\frac{\beta b}{\alpha h}(\lambda \alpha h-h)=\beta b\left(\lambda-\frac{1}{\alpha}\right) \\
& F_{c}=0.567 f_{c k}\left\{0.5\left(\beta b_{1}+\lambda \beta b\right) h\right\} \\
& M_{x c}=F_{c} *(0.5 h-\bar{y}) \\
& M_{y c}=F_{c} *(0.5 b-\bar{x})
\end{aligned}
$$

The location of the centroid with respect to the right face of the trapezium is:

$$
\bar{x}=\frac{\beta}{3} \frac{\left(b_{1}^{2}+\lambda^{2} b^{2}+\lambda b_{1} b\right)}{\left(b_{1}+\lambda b\right)}
$$

The location of the centroid with respect to the top face of the trapezium is:

$\bar{y}=\frac{h}{3} \frac{\left(2 b_{1}+\lambda b\right)}{\left(b_{1}+\lambda b\right)}$

\section{Case $4(\lambda \beta>1.0$ and $\lambda \alpha>1.0$}

This case represents the column section subjected to a relatively large axial compressive force and small moments about the $\mathrm{x}$ and $\mathrm{y}$ axes. The concrete compression area has a pentagonal shape as shown in Figure 7. 
Figure 7. Neutral Axis Position for Case 4

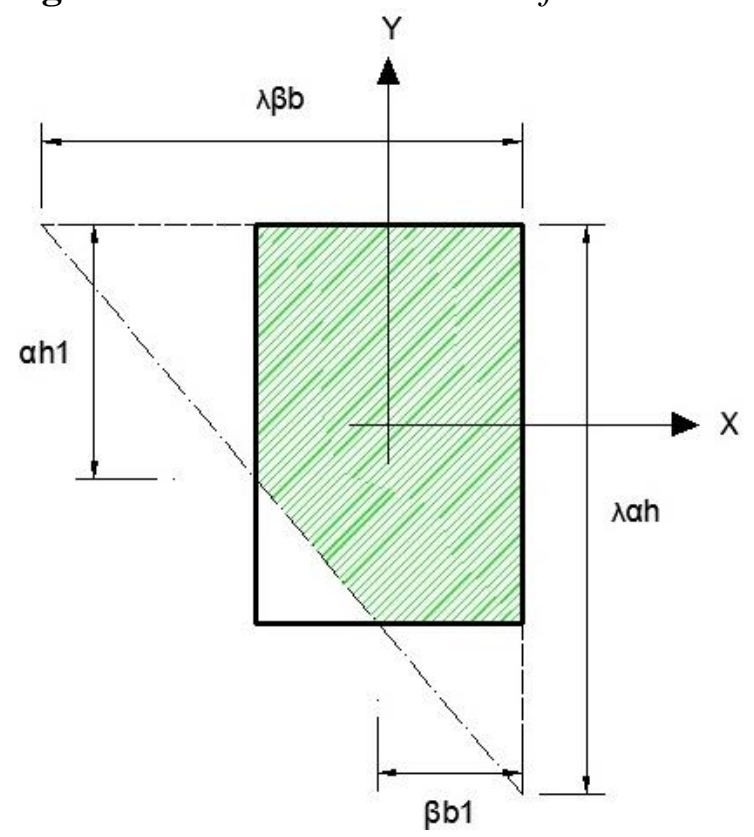

Compression over the entire area of the column will not give growth to any moment. The moment is initiated purely by the tension in the triangular area.

$$
\begin{aligned}
& \alpha h 1=\frac{\alpha h}{\beta b}(\lambda \beta b-b)=\alpha h\left(\lambda-\frac{1}{\beta}\right) \leq h \\
& \beta b 1=\frac{\beta b}{\alpha h}(\lambda \alpha h-h)=\beta b\left(\lambda-\frac{1}{\alpha}\right) \leq b \\
& F_{c}=0.567 f_{c k}\left\{b h-0.5\left(h-\alpha h_{1}\right)\left(b-\beta b_{1}\right)\right\} \\
& M_{x c}=0.567 f_{c k} 0.5\left(h-\alpha h_{1}\right)\left(b-\beta b_{1}\right)\left\{0.5 h-\frac{1}{3}\left(h-\alpha h_{1}\right)\right\} \\
& M_{y c}=0.567 f_{c k} 0.5\left(h-\alpha h_{1}\right)\left(b-\beta b_{1}\right)\left\{0.5 b-\frac{1}{3}\left(b-\beta b_{1}\right)\right.
\end{aligned}
$$

Case 5 (Section under Full Compression)

As shown in Figure 8, the whole section is under the full compression and the section carries a uniform compressive stress of $0.567 \mathrm{f}_{\mathrm{ck}}$. 
Figure 8. Neutral Axis Position for Case 5

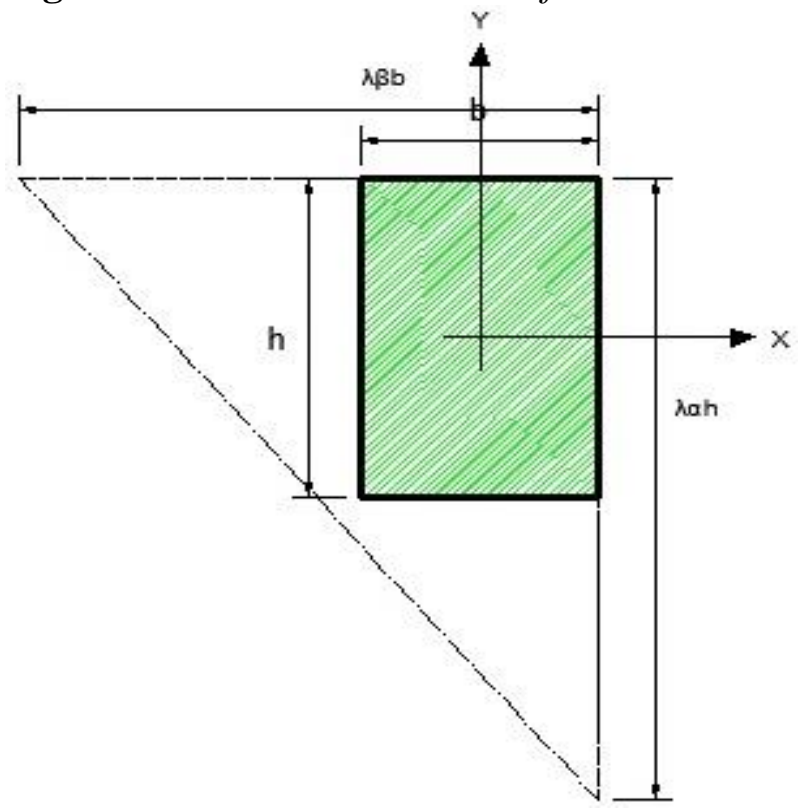

Thus, the concrete force is:

$\mathrm{F}_{\mathrm{c}}=0.567 \mathrm{f}_{\mathrm{ck}} \mathrm{b} * \mathrm{~h}$

Compression over the entire area of the column will not give growth to any moment, i.e. $\mathrm{M}_{\mathrm{xc}}=\mathrm{M}_{\mathrm{yc}}=0$.

Having calculated the forces and moments resisted by the materials forming the section, it is very easy to find the ultimate axial load $\mathrm{N}_{\mathrm{r}}$ and the ultimate moments $\mathrm{M}_{\mathrm{rx}}$ and $\mathrm{M}_{\mathrm{ry}}$ capacities of the section by applying an equilibrium condition. In other words, these resistant forces should be equal or greater than the applied design forces on the section.

$\mathrm{N}_{\mathrm{r}}=\mathrm{F}_{\mathrm{c}}+\mathrm{F}_{\mathrm{s}} \geq \mathrm{N}_{\mathrm{d}}$
$\mathrm{M}_{\mathrm{rx}}=\mathrm{M}_{\mathrm{xc}}+\mathrm{M}_{\mathrm{xs}} \geq \mathrm{M}_{\mathrm{dx}}=\mathrm{N}_{\mathrm{d}} * \mathrm{e}_{\mathrm{y}}$
$\mathrm{M}_{\mathrm{ry}}=\mathrm{M}_{\mathrm{yc}}+\mathrm{M}_{\mathrm{ys}} \geq \mathrm{M}_{\mathrm{dy}}=\mathrm{N}_{\mathrm{d}} * \mathrm{e}_{\mathrm{x}}$

\section{Optimisation Formulation}

The structural optimisation problem can mathematically be expressed as, (Rao, 2009):

Find the set of $n$ design variables,

$\{\mathrm{x}\}=\left\{\mathrm{x}_{1}, \mathrm{x}_{2}, \mathrm{x}_{3}, \ldots . . \mathrm{x}_{\mathrm{n}}\right\}$

which minimises the objective function defined by:

$\mathrm{Z}=\mathrm{f}(\{\mathrm{x}\})=\mathrm{f}\left(\mathrm{x}_{1}, \mathrm{x}_{2}, \mathrm{x}_{3}, \ldots \ldots, \mathrm{x}_{\mathrm{n}}\right)$

subjected to $(\mathrm{m})$ behavioural (implicit) constraints,

$g_{j}(\{x\})=g_{j}\left(x_{1}, x_{2}, x_{3}, \ldots \ldots . ., x_{n}\right) \leq 0$

and (n) side (explicit) constraints,

$\{\mathrm{L}\} \leq\{\mathrm{x}\} \leq\{\mathrm{U}\}$ 


\section{Design Variables}

For the reinforced concrete rectangular column under the axial compressive load and biaxial bending moment, the design variables are the cross sectional area of the column (width and depth) and the area of the steel reinforcement. Furthermore, the parameters $\alpha$ and $\beta$ that affect the position and direction of the neutral axis are also considered as design variables in this study. This is to avoid finding their values through solving highly nonlinear simultaneous equations that might affect the convergence of the solution. Thus, there are five design variables to be taken into account which are:

$\mathrm{x}_{1}=\mathrm{h} ; \mathrm{x}_{2}=\mathrm{b} ; \mathrm{x}_{3}=$ As $; \mathrm{x}_{4}=\alpha ; \mathrm{x}_{5}=\beta$

\section{Objective Function}

The objective function considered is the minimum cost per unit length of the column. This comprises the cost of concrete and steel materials as well as the cost of formwork (Fedghouche and Tiliouine, 2012). Thus:

\section{$\mathrm{Z}=\mathrm{C}_{\mathrm{c}} \mathrm{bh}+\mathrm{C}_{\mathrm{s}} \gamma_{\mathrm{s}}$ As $+2 \mathrm{C}_{\mathrm{f}}(\mathrm{b}+\mathrm{h})$}

By dividing both sides of Eq. 33 by $\mathrm{C}_{\mathrm{c}}$, and expressing deign variables by their generic terms, the objective function will take the form:

$$
\frac{\mathrm{z}}{\mathrm{c}_{\mathrm{c}}}=\mathrm{x}_{1} \mathrm{x}_{2}+\frac{\mathrm{c}_{\mathrm{g}}}{\mathrm{c}_{\mathrm{c}}} \gamma_{\mathrm{g}} \mathrm{x}_{3}+2 \frac{\mathrm{c}_{\mathrm{f}}}{\mathrm{c}_{\mathrm{c}}}\left(\mathrm{x}_{1}+\mathrm{x}_{2}\right)
$$

Where

$\mathrm{Z} \quad$ is the minimum cost of the column section

$\mathrm{C}_{c} \quad$ is the cost of concrete per $\mathrm{m}^{3}$

$\mathrm{C}_{\mathrm{s}} \quad$ is the cost of steel per ton

$\mathrm{C}_{\mathrm{f}} \quad$ is the cost of formwork per $\mathrm{m}^{2}$

As is the total area of steel

$\gamma_{s} \quad$ is the unit weight of steel $=7.85 \mathrm{ton} / \mathrm{m}^{3}$

\section{Constraints}

The constraints were set to satisfy the requirements of EC2 which are:

$$
\begin{array}{ll}
\mathrm{g}_{1}: & \mathrm{N}_{\mathrm{d}}-\mathrm{N}_{\mathrm{r}} \leq 0 \\
\mathrm{~g}_{2}: & \mathrm{M}_{\mathrm{dx}}-\mathrm{M}_{\mathrm{xr}} \leq 0 \\
\mathrm{~g}_{3}: & \mathrm{M}_{\mathrm{dy}}-\mathrm{M}_{\mathrm{yr}} \leq 0 \\
\mathrm{~g}_{4}: & \mathrm{x}_{3}-0.002 \mathrm{x}_{1} \mathrm{x}_{2} \geq 0 \\
\mathrm{~g}_{5}: & \mathrm{x}_{3}-0.04 \mathrm{x}_{1} \mathrm{x}_{2} \leq 0 \\
\mathrm{~g}_{6}: & \mathrm{x}_{3} \geq 452 \\
\mathrm{~g}_{7}: & \mathrm{x}_{1} \geq 150 \\
\mathrm{~g}_{8}: & \mathrm{x}_{1} \leq 2000 \\
\mathrm{~g}_{9}: & \mathrm{x}_{2} \geq 150 \\
\mathrm{~g}_{10}: & \mathrm{x}_{2} \leq 2000 \\
\mathrm{~g}_{11}: & \mathrm{x}_{3} \leq 15000 \\
\mathrm{~g}_{12}: & \mathrm{x}_{1}-\left(2 \mathrm{x}_{2} \text { or } 3 \mathrm{x}_{2}\right) \leq 0 \\
\mathrm{~g}_{13}: & \mathrm{x}_{4} \geq 0 \\
\mathrm{~g}_{14}: & \mathrm{x}_{4} \leq 5 \\
\mathrm{~g}_{15}: & \mathrm{x}_{5} \geq 0
\end{array}
$$


$g_{16}: \quad x_{5} \leq 5$

Constraints $g_{1}$ to $g_{3}$ express the ability of the column to resist the applied loading. Constraints $g_{4}$ and $g_{5}$ define the limitation of the reinforcement ratio in the column section. EC2 limits the longitudinal reinforcement in the compression member to be between a minimum of $0.2 \%$ and a maximum of $4 \%$ of the gross area of the concrete section. Furthermore, the minimum bar diameter for longitudinal reinforcement, as specified by EC2, is $12 \mathrm{~mm}$ (i.e. minimum bar area $=113 \mathrm{~m}^{2}$ ). This implies that the total steel area column cross section should not be less than $\left(4 \times 113=452 \mathrm{~mm}^{2}\right)$ which is reflected by the constraint $g_{6}$. The constraints $g_{7}$ up to $g_{11}$ define the lower and upper limits of the cross sectional dimensions ( $b$ and $h$ ) and the area of steel As. Constraint $\mathrm{g}_{12}$ sets the limit of height to width ratio for a rectangular column section. Two arbitrarily cases were taken into account which are: $h \leq 2 \mathrm{~b}$ and $\mathrm{h} \leq 3 \mathrm{~b}$. Finally, the constraints $g_{13}$ up to $g_{16}$ describe the lower and upper limits of the parameters $\alpha$ and $\beta$. This is to cover the full range of load application from a case of pure axial compression force to pure bending moments.

\section{Design Parameters}

The design parameters that were kept constant for all examples solved are the concrete compressive strength $\left(f_{c k}=30 \mathrm{MPa}\right)$, the characteristic yield strength of steel $\left(\mathrm{f}_{\mathrm{yk}}=460 \mathrm{MPa}\right)$ and the concrete cover to the centre of steel area $\left(\mathrm{d}^{\prime} \mathrm{x}=60 \mathrm{~mm}\right.$ and $\left.\mathrm{d}^{\prime} \mathrm{y}=60 \mathrm{~mm}\right)$.

\section{Optimisation Tool and Technique}

A nonlinear mathematical programming technique known as the Generalised Reduced Gradient (GRG) method was employed due to its outstanding merits as explained earlier in the introduction. For the purpose of implementing the GRG method, Solver add-in of Microsoft Excel was utilised as an optimisation tool.

To use the Excel Solver two main steps need to be followed:

- Preparation of an Excel worksheet for the problem, identifying the cells allocated for the design variable, objective function and the constraints. Moreover, all the necessary required intermediate calculations (e.g. formula and if conditions) should be rightly and systemically placed in certain cells.

- The Solver is then invoked, which results in the display of the Solver Parameters dialog box as shown in Figure 9. In this box, the actual problem that has to be solved is defined. The cells that contain the variables, objective function and the cells defining different constraints for the problem are identified. 
Figure 9. Solver Parameter Dialogue Window

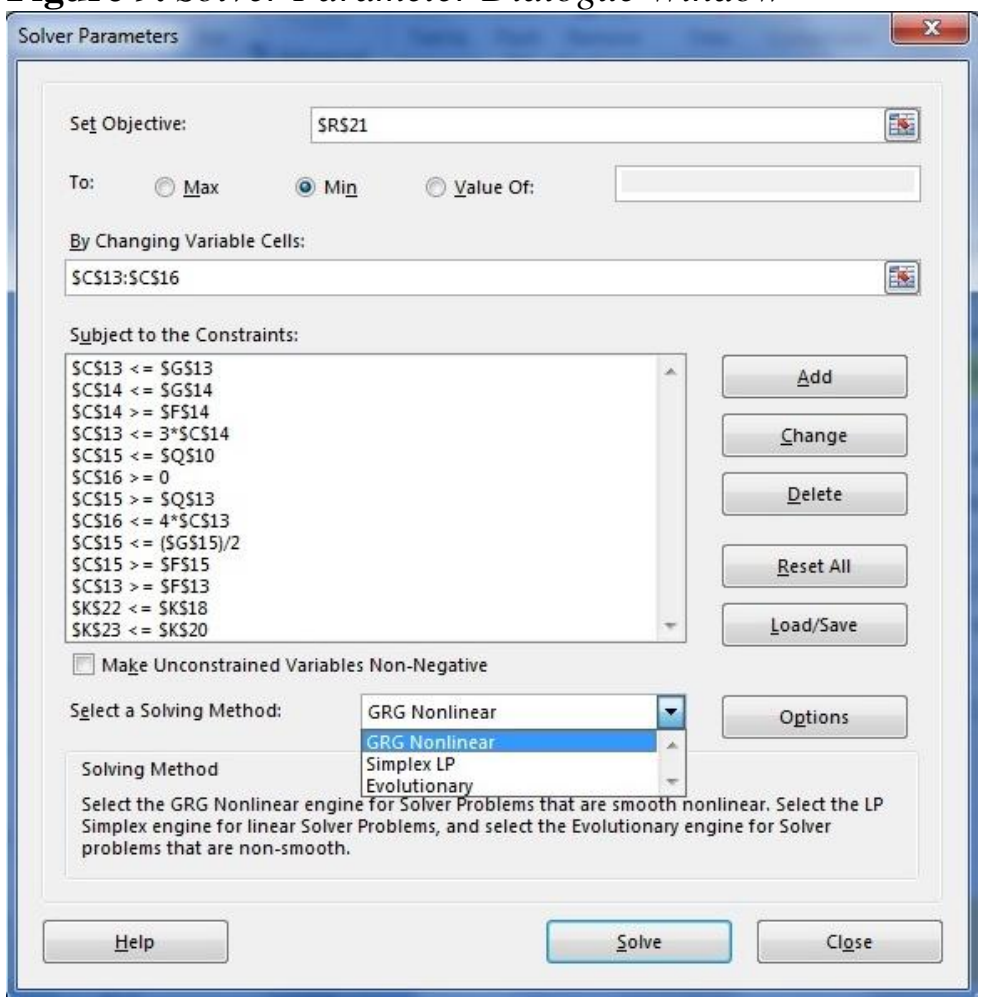

\section{Results and Discussion}

Columns have practically several design parameters, thus, the adjustment of which may affect the results of optimisation problems. Therefore, the sensitivity analysis was carried out to test the effects of steel to the concrete cost ratios $\left(\mathrm{C}_{\mathrm{s}} / \mathrm{C}_{\mathrm{c}}\right)$ and the depth to width ratio $(\mathrm{h} / \mathrm{b})$ on the optimum cost of the concrete columns. Accordingly, a large number of examples were solved for a range of applied axial forces between $100 \mathrm{kN}$ to $2000 \mathrm{kN}$, having different eccentricities $\mathrm{e}_{\mathrm{x}}$ and $\mathrm{e}_{\mathrm{y}}$ of 100, 200, 400, 600, 800, 1000mm. Furthermore, three different $\mathrm{C}_{\mathrm{s}} / \mathrm{C}_{\mathrm{c}}$ ratios of 5,10 and 20 ; and two different $\mathrm{h} / \mathrm{b}$ of 2 and 3 were taken into account. Considering all these combinations resulted in an enormous row of data which helped in preparing optimum design charts. Typical examples of optimum design charts constructed are shown in Figures 10-12. A full set of optimum design charts is available in reference (Seyan, 2014).

Figures 10-12 illustrate respectively the variation of the optimum depth, width and the area of steel of the column cross section versus the applied axial load for a given set of the $\mathrm{h} / \mathrm{b}$ ratio, $\mathrm{C}_{\mathrm{s}} / \mathrm{C}_{\mathrm{c}}$ ratio, $\mathrm{e}_{\mathrm{x}}$ and $\mathrm{e}_{\mathrm{y}}$. It can be clearly seen that the optimum depth, width and area of steel are all steadily and logically increasing as the applied axial compression force increases. For relatively low eccentricity $\left(e_{x}=200 \mathrm{~mm}\right)$, no difference in the optimum depth and width can be noticed for both $\mathrm{h} / \mathrm{b}$ ratios. Whereas remarkable difference can be observed as the eccentricity becomes larger $\left(e_{x}=1000 \mathrm{~mm}\right)$. As the eccentricity in the $y$ 
direction $\left(\mathrm{e}_{\mathrm{y}}\right)$ increases from $200 \mathrm{~mm}$ to $400 \mathrm{~mm}$, the optimum depth starts to decrease while the optimum depth increases.

Figure 10. Optimum Depth (h) of Section for $C_{s} / C_{c}=5$

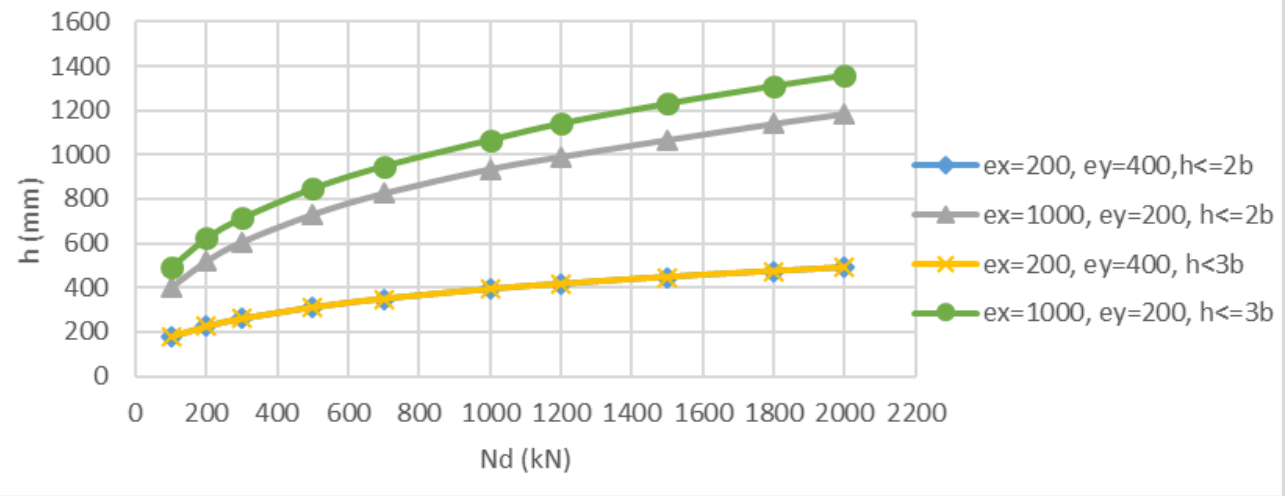

Figure 11. Optimum Width (b) of Section for $C_{s} / C_{c}=5$

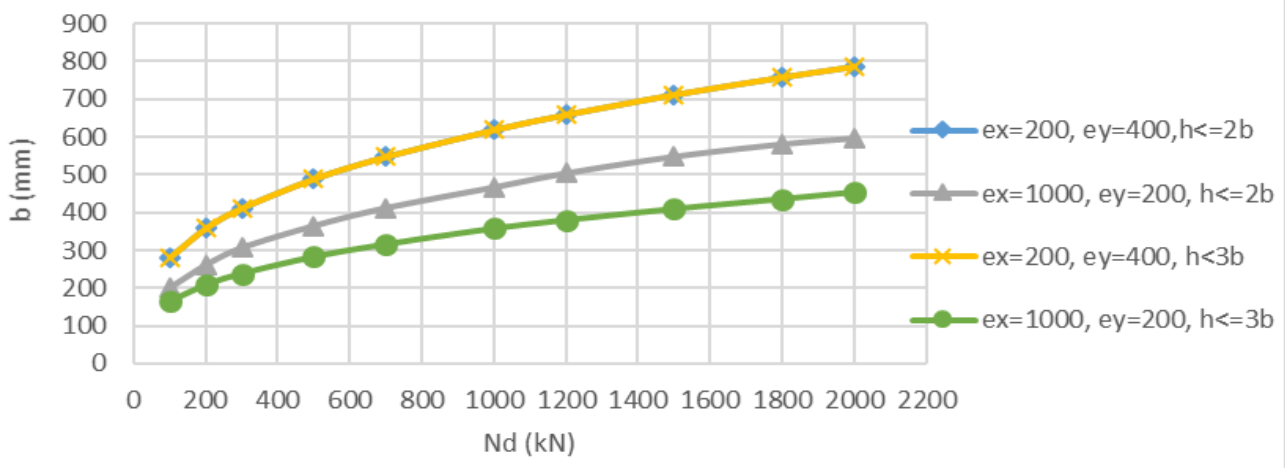

Figure 12. Optimum Area of Steel (As) of Section for $C_{s} / C_{c}=5$

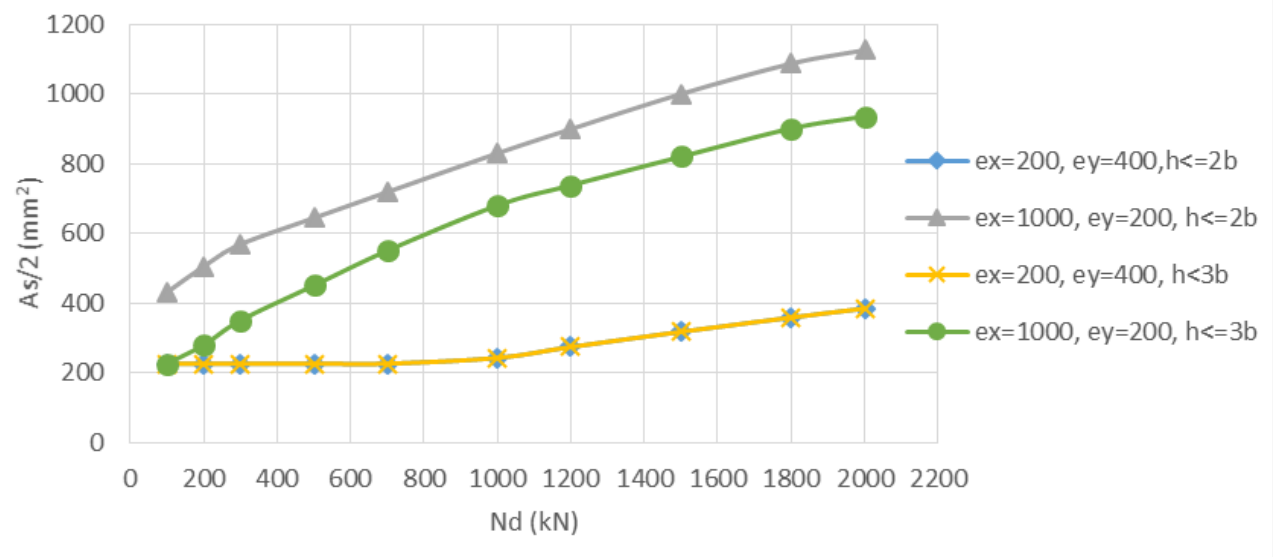


The cost of the section increases proportionally with the increase of $\mathrm{C}_{\mathrm{s}} / \mathrm{Cc}$, as indicated in Figures 13 and 14. The optimum cost of the column section increases with the cost ratio $\mathrm{C}_{\mathrm{s}} / \mathrm{C}_{\mathrm{c}}$ from 5 to 10 and 20 , for the same $\mathrm{h} / \mathrm{b}$ ratio. The effect is more obvious with larger loads and higher eccentricities.

Figure 13. Minimum Cost versus Applied Load, Biaxial Column, $h \leq 2 b$

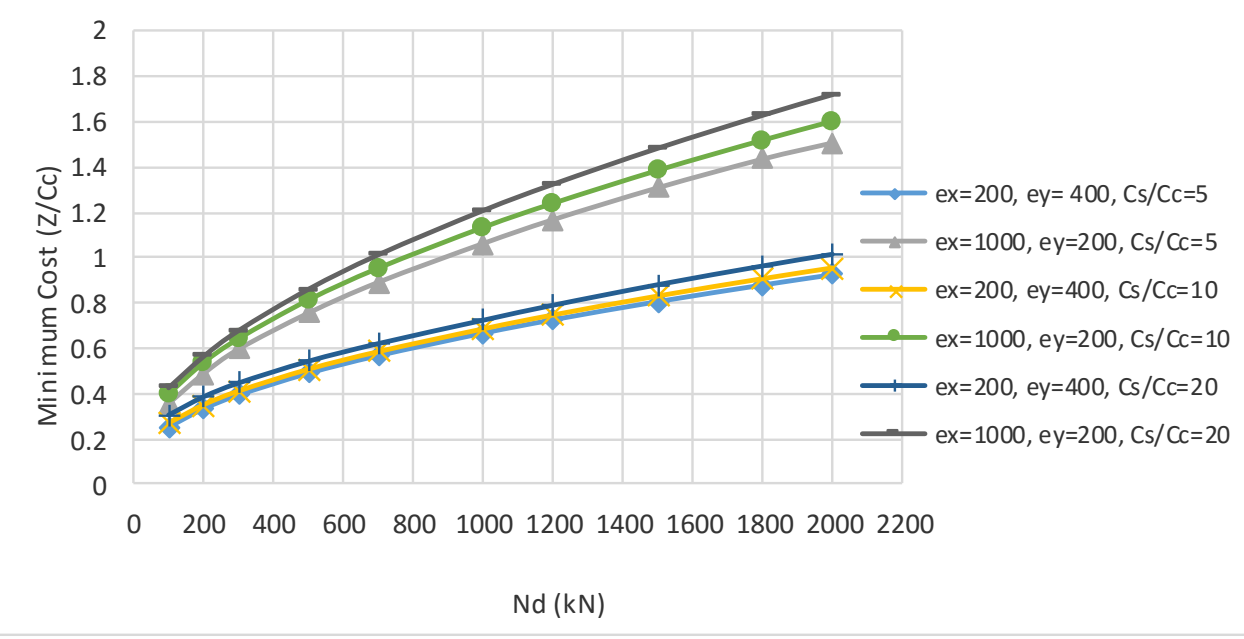

Figure 14. Minimum Cost versus Applied Load, Biaxial Column, $h \leq 3 b$

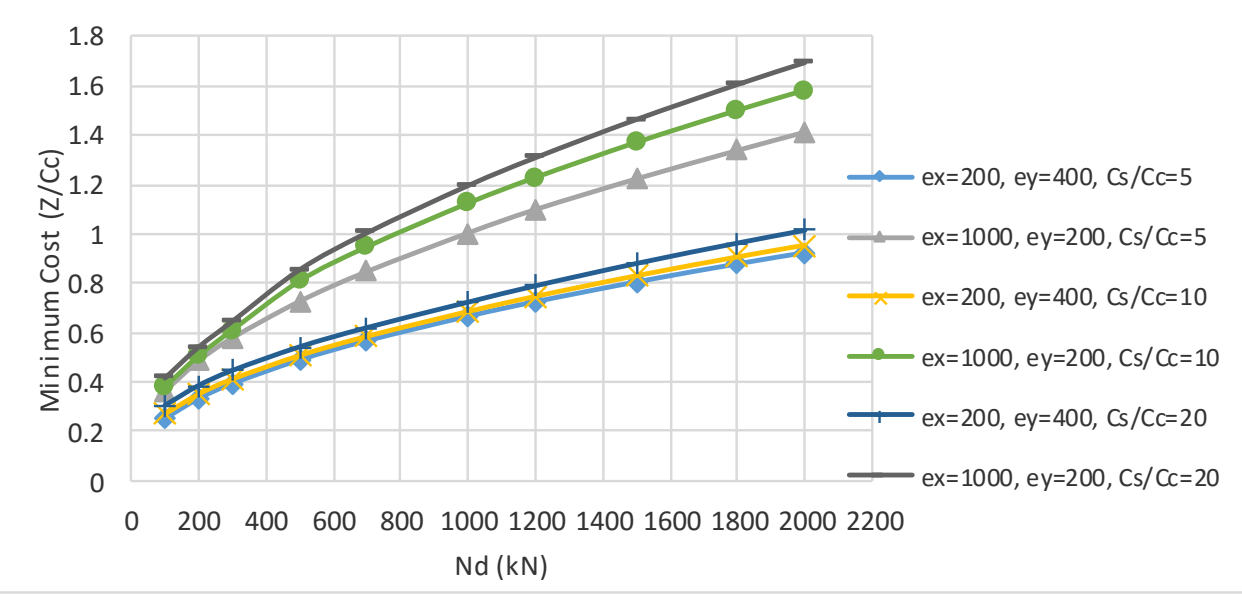

\section{Conclusions}

A wide range of practical cases in terms of the depth to width ratio, steel to concrete cost ratios, and eccentricities in both $\mathrm{x}$ and $\mathrm{y}$ directions cases, were solved, from which the following conclusions can be extracted: 
- It was demonstrated that the Excel Solver add-in tool with its embedded GRG function can be efficiently and powerfully used for carrying the cost minimisation of the reinforced concrete column subjected to axial compression and biaxial bending moments.

- The optimum cost of the column section increases with the cost ratio $\mathrm{Cs} / \mathrm{Cc}$ from 5 to 10 and 20, for the same h/b ratio. Furthermore, the influence cost ratio, $\mathrm{Cs} / \mathrm{Cc}$, is more obvious at larger loads and higher eccentricities.

- Optimum design charts were prepared that allow structural engineers to attain optimum reinforced concrete column cross-sectional dimensions and the reinforcement area needed, which reduces effort requirements and saves time for calculation.

\section{References}

Arora, J. S. 2012. Introduction to Optimisation Design. Second Edition, Elsevier.

Belegundu, A. D. and Chandrupatla, T. R. 2011. Optimisation Concepts and Applications in Engineering. Second Edition. Cambridge: Prentice Hall.

Bhalchandra, S. A. and Adsul, P. K. 2012. Cost Optimisation of Doubly Reinforced Rectangular. International Journal of Modern Engineering Research (IJMER), 2(5), pp. 3939-3942.

Bhatt, P., McGinley, T. J. and Choo, B. S. 2013. Reinforced Concrete Design to Eurocodes: Design theory and Examples. Fourth Edition, Taylor \& Francis Group, Ney York.

Eurocode 2, 2004. Eurocode 2 - Design of concrete structures, Part 1: General Rules and Rules for Buildings. BSI British Standard, BS EN 1992-1.

Faluyi, F. and Arum, C. 2012. Design Optimisation of Plate Girder Using Generalised Reduced Gradient and Constrained Artificial Bee Colony Algorithms. International Journal of Emerging Technology and Advanced Engineering, 2(7), pp. 304-312.

Fedghouche F. and Tiliouine, B. 2012. Minimum Cost Design of Reinforced Concrete T-Beams at Ultimate Loads Using Eurocode2. Engineering Structures, 42, pp. 43-50.

Rafiq, M. Y. 1995. Genetic Algorithms in Optimum Design, Capacity Check and Final Detailing of Reinforced Concrete Columns. Transactions on the Built Environment, 13(1), pp. 161-169.

Rafiq, M. Y. and Southcombe, C. 1998. Genetic Algorithms in Optimal Design and Detailing of Reinforced Concrete Biaxial Columns Supported by a Declarative Approach for Capacity Checking. Computers and Structures, 69(1), pp. 443-457.

Rao, S. S. 2009. Engineering Optimisation Theory and Practice, Fourth edition, John Wiley and Sons, New Jersey.

Ravindran, A., Ragsdell, K. M. and Reklaitis, G. V. 2006. Engineering optimisation: Methods and Applications. Second Edition, John Wiley \& Sons, New Jersey.

Seyan, D. 2014. Optimum Design of Reinforced Concrete Columns According to ACI and EC2 Codes. MSc Thesis, Nottingham Trent University, UK.

Yeniay, O. 2005. A Comparative Study on Optimisation Methods for the Constrained Nonlinear Programming Problems, Hindawi Publishing Corporation, Mathematical problems in Engineering: 2 pp. 165-173. 
